\title{
HEALTHY ROUTES FOR ACTIVE MODES IN SCHOOL JOURNEYS
}

\author{
P. RIBEIRO \& J.F.G. MENDES \\ C-TAC, Department of Civil Engineering, University of Minho, Portugal.
}

\begin{abstract}
In recent years, walking and cycling to school have decreased conversely to the use of private cars due to its greater level of comfort and safety. However, the use of active modes of transport for short journeys is more economically and socially adequate as well as a healthier way of traveling. Active modes of transport can be defined as means of travel and transportation at low speed, which take up little space on the road, are air and noise non-pollutant, thus being regarded as more sustainable and a real alternative to cars. On the other hand, urban sustainable mobility implies the definition of policies and actions that rely on the promotion of less pollutant, economic, and more equitable modes of transport. To promote this modal shift, some policies focus on the facilities and urban form improvements to increase safety, namely for pedestrians. In this paper a different way to promote the use of active modes in school journeys is proposed and presented, which essentially uses and integrates information from noise and air pollution in the route-planning process to generate healthy routes. The concept of generation of healthy routes was triggered by the need to reduce the exposure to noise and air pollution in school journeys, which can affect the children's health and quality of life. The healthy route model involves the contamination of the distances of the transport network, according to the urban environmental noise levels and the concentration of particles - PM10, thus allowing the definition of the less polluted, less noisy and healthier route for active modes. The performance of the model is assessed by calculating the noise and air pollution exposure rates in the obtained routes, in comparison with the shortest route. To validate the model and its potential for the promotion of active modes, a case study is presented in a city center located in North of Portugal for three different school journeys.
\end{abstract}

Keywords: Active modes, air pollution, cyclists, health, noise, pedestrians, PM10.

\section{INTRODUCTION}

The integration of sustainability principles in urban development comprises the reduction of the influence of individual motorized traffic and, consequently, the promotion of the use of public transport and active modes of transport. It is widely acknowledged that cars have dominated journeys in the urban environment. As a result, cities have been designed to comply with such usage, with clear disadvantages toward other modes of transport.

Active modes of transport can be defined as means of travel and transportation at low speed, which take up little space on the road, are air and noise non-pollutant, thus being regarded as economically, socially and environmentally valuable and a real alternative to cars.

The promotion of active mobility has focused on creating new infrastructures and in strengthening circulation safety. However, the modal shift between cars and active modes has not yet occurred and in certain cases has become more difficult to achieve.

Given the main functional characteristics of walking and cycling, the environmental dimension is very important and should serve not only as a reason for its promotion but also as an active and decisive factor in its effective usage.

Current societies have more access than ever before to diverse sources of information and can make use of such information by means of web-services on fixed or mobile devices. The existing web-based route planners and, more recently, real-time navigation systems enable to plan and adjust a journey providing comfort and a sense of safety. These services can also be applied to promote active mobility in cities, by means of its implementation in smartphones or similar devices. 
One of the objectives of this paper is the application of a planning and route generation model in urban areas to be implemented as a web-based service through the use of e-planning and mobile technologies. Conventional web-route planners are mainly designed for car, public transport, and walking trips, while cycling rarely is an available option. The main function of these conventional planners consists in finding the shortest, fastest, or least expensive route. For similar purposes, navigation stand-alone devices are even more focused on a specific type of users, mainly for drivers.

This work integrates environmental aspects in the decision-making process of travelling in a city, with particular focus on school journeys, thus taking into consideration the fact that students as pedestrians and/or cyclists are the most vulnerable users of the transport system in several aspects, mainly those related with air pollution and noise. Active users could be irreversibly affected during their life because they travel as commuters through polluted urban streets due to the lack of information and awareness on the impacts that those everyday routes have on their cardiovascular and respiratory systems.

In this paper, the concept, development, and application of a model capable of generating healthy routes will be presented, which can be used in a route planner dedicated to active modes of transport, taking into consideration the main environmental characteristics of the urban spaces, namely in school journeys. Through the production of long-term maps of air pollution and noise, it is possible to obtain the necessary data for the development of an environmental impedance function to be applied in the street network, by means of the contamination of the distances of each generated route. The use of a Geographic Information System (GIS) extension dedicated to the calculation of routes will allow to achieve the less polluted, less noisy, and the healthiest route, in other words, the more sustainable routes, thus providing an environmental and healthy better solution for pedestrians and cyclists.

The conceptual formulation of the model of generation of healthy routes for soft active modes of transport to be used in digital planning devices, such as dedicated web platforms, and Global Positioning System (GPS) navigation systems, was presented in Ribeiro and Mendes [1], resulting in an innovative and user-friendly solution for pedestrians and cyclists.

An application case study was developed to present the effects that students can be exposed to during their daily journeys to different schools in the central area of the city of Braga located in northern Portugal. For this, the less polluted, noisiest and healthiest route will be calculated from a specific neighborhood to those schools and its environmental performance will be evaluated through a particulate matter (PM10) and noise indicator.

\section{ACTIVE MODES - HEALTH AND SUSTAINABILITY}

Walking and cycling have different rates of use across European countries and in this context Portugal occupies almost the end of the tail, especially when compared with countries such as Denmark or the Netherlands $[2,3]$.

According to the World Health Organization, short trips taken in motorized vehicles should be potentially replaced by walking and cycling, with clear benefits for human health due to the achievement of permanent physical activity. For a long time, several studies related with public health risk have shown some inertia on the recognition of the global impact in human health of the generalized use of motorized traffic (e.g. accidents, air pollution and noise) for most activities in urban environments. However, the use of active modes of transport is already a new trend on practices and policies toward the achievement of a more sustainable urban mobility.

Sustainability is an important vector that guides the implementation of functional and structural changes in consolidated urban spaces. Issues associated with climate change, pollution, and the reduction of natural resources are subjected to constant attention and concern by the public and have 
a growing impact on people's behavior, habits, and consumption patterns. Thus, the promotion of living standards and more sustainable ways of traveling can be achieved through the introduction of significant improvements in the planning and design stages, taking into account the important contributions of several authors such as Hall and Sussman [4], Jones et al. [5] and WCED [6].

According to Federal Highway Administration (FHWA) [7], the introduction of the bicycle was an important innovation for the promotion of social inclusion. Some studies show that when per capita income increases, the use of private car also increases, while walking and cycling decrease. This situation is similar in some small- and medium-sized cities of Portugal [8].

The implementation of short-term travels on foot or by bicycle can bring socioeconomic, environmental and health benefits, which are evidenced mainly in the reduction of air pollutant emissions and in the congestion of urban road networks [7].

Several studies have shown significant benefits that derive from the regular and daily practice of physical exercise. Walking is the primary option to increase physical activity in sedentary populations [9]. Even moderate or low levels of physical activity performed regularly can reduce the risk of coronary heart disease, diabetes, stroke, and other chronic diseases.

Additionally, it reduces the costs related to healthcare, contributing to greater autonomy and independence of people, especially at advanced ages. On the other hand, walking allows a greater interaction between people, as they socialize during these trips, especially in comparison to private car travel.

In recent years, the European Union (EU) has supported projects that aimed at promoting the use of soft modes of transport through project funding within the Fourth and Fifth Framework for Research Program. It also should be noted that part of the Seventh European Program, which runs between 2007 and 2013, is oriented to promote a more sustainable transport system, in particular in the area of surface transports, which includes walking and cycling, through the establishment of a 'greener' transport system, modal shifting, and fluidity in main transport corridors. Thus, it is intended to ensure a more sustainable urban mobility and to increase the competitiveness of the sector.

Certainly, some measures and programs aiming at the promotion of the use of soft modes will focus on the improvement of infrastructure and facilities [10], mainly on footways and cycle lanes. However, this may be insufficient and lead to high cost solutions, without relevant turnover in terms of an increased number of users. It is necessary that the promotion of the use of soft modes is efficient and effective, leading to an increase of frequent users, aware of their role in the achievement of an urban sustainable mobility.

It is expected that, given the current social, economic, and environmental situations in the world, the use of alternative modes of transport becomes the first modal choice, instead of an alternative to private cars. However, it is necessary that people govern their daily mobility patterns by principles of equity and sustainability, which can only be acquired through education, training, and, especially, with high quality information.

Pedestrians and cyclists can represent a 'green', environmentally friendly and healthy brand. For this, it is necessary to develop information and decision-making tools regarding the selection of routes, especially in urban areas.

\section{ROUTE PLANNING FOR ACTIVE MODES}

Associated with the introduction of new technologies in the operation of the transportation system, the information system is a key tool for the proper functioning of the entire mobility system, especially when it has a multimodal character. Route planning is an increasingly common reality, both for long or short journeys (suitable for urban areas). 
A properly informed citizen is capable of choosing the best travel option, although the selection process is usually very individual, and aims at achieving the most convenient journey for its purposes. In the case of trips exclusively taken with a single mode of transport, the public will try to get as much information about this mode of transport as possible. In such cases, it is possible to highlight important logistical interfaces represented by websites, namely those provided by Google maps [11] for entire cities and countries that provide clear and objective information, where access is easy and sometimes immediate. Thus, it is possible to conclude that, for an information system to be efficient and equitable, it must have dynamic and integrated technological support tools for its users, with interactive planning and navigation features for the various transport systems.

In the specific case of Google maps, it is possible to find a route planner that allows traveling in three different modes of transportation, which includes walking as it can be seen in Fig. 1, where three different routes are displayed based on the optimization of the travel time between origins and destinations.

Route planners that include the option of walking are easy to find although cycling is rarely available, as only a few organizations have this option, namely Transport for London [1]. On the other hand, planning and navigation devices available for active modes are usually associated with sports activities.

Given the current advances in terms of routing and navigation, a new approach in route planning should include optimization criteria which should be based not only on issues related to the length and travel time, as is usually observed in systems planning and navigation for cars, like on standalone devices of tomtom, Ndrive among others.

Therefore, in this research a model was developed and applied for the generation of routes integrating an innovative set of criteria appropriate to the reality of pedestrians and cyclists, through the integration of environmental factors in the selection process, considering the impact of air pollution and noise, thus originating the so-called healthy routes.

The promotion of walkability and bikeability can improve the quality of life in urban areas. The basic features of a walkable urban road environment are the following: accessibility, convenience, attractiveness, road and personal safety $[12,13]$. Healthy routes can be seen as aligned with these

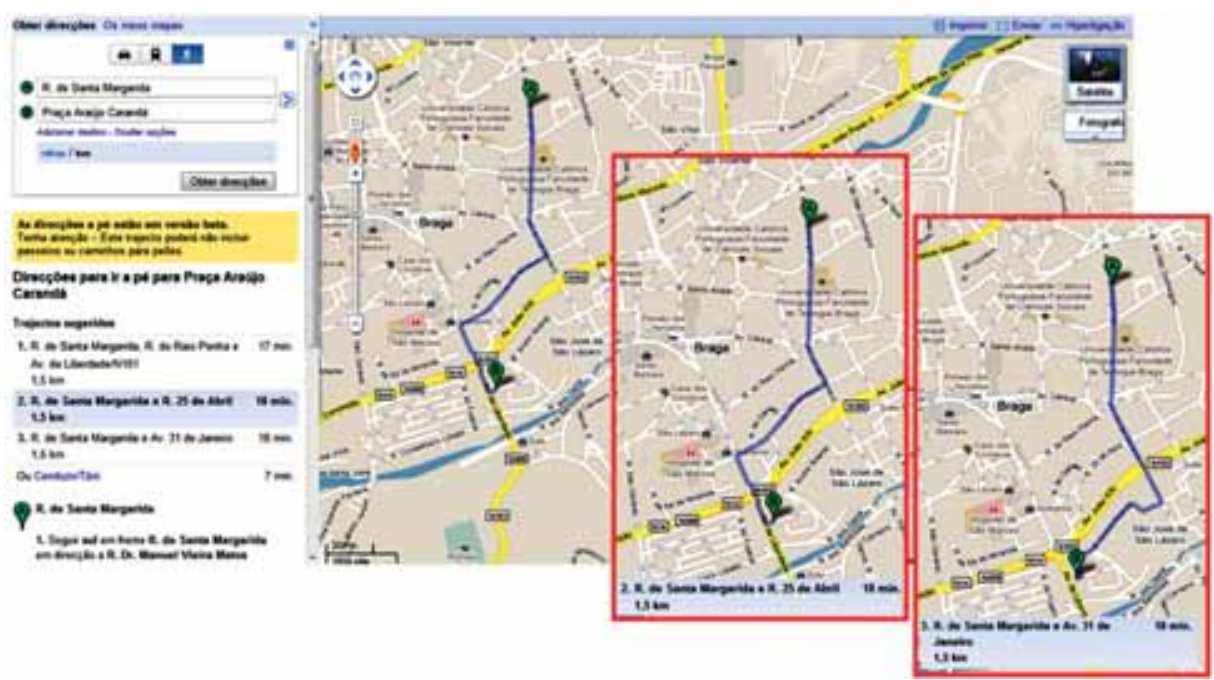

Figure 1: Example of a pedestrian route using Google route planner [11]. 
concepts because they also aim to achieve better health for pedestrians and cyclists and, in a broader sense, to all citizens.

\section{DESCRIPTION OF THE HEALTHY ROUTES MODEL}

The concept of healthy routes, also sometimes referred to as green, clean, safe or sustainable routes for walking and cycling, considers in the definition of a itinerary a set of impedances of environmental nature and certain aspects associated with health, aiming to provide a comparison between different routes toward achieving the healthiest route.

The model has three distinct phases: (i) the generation of the pollution map; (ii) the contamination of distances; (iii) the generation of healthy routes, according to the diagram in Fig. 2.

In urban areas, some pollutants are more frequently observed than others mainly due to different sources of pollution and for most of them the principal source is the motorized traffic. For this reason, in this work four types of air pollutants were studied and characterized: PM10, benzene, nitric oxides (NOx) and sulfur dioxide $\left(\mathrm{SO}_{2}\right)$. According to the World Health Organization [14] the principal source of these pollutants due to human usage is the motorized traffic except for $\mathrm{SO}_{2}$, for which industries are the main responsible for its presence in the atmosphere. In this work, pollutants such as carbon monoxide $(\mathrm{CO})$ were not characterized since it was not possible to model its dispersion due to software restrictions.

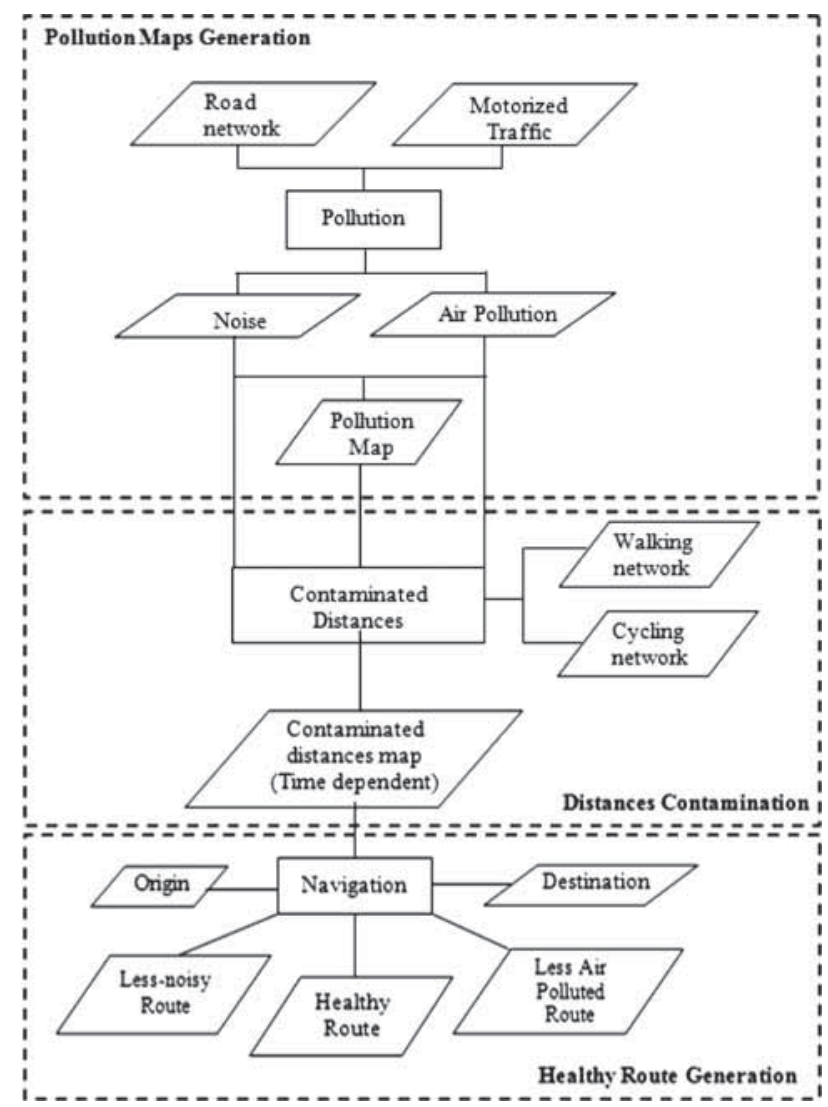

Figure 2: Flow diagram for the generation of healthy routes for soft modes [1, 14]. 
According to the European Environment Agency, long-term particulate matter (PM) and noise represent an important sum of years of potential life lost due to premature mortality and years of productive life lost due to disability - the DALY - that considers in its calculation the mortality, (loss of) mobility, self-care, daily activities, pain/discomfort, anxiety/depression, and cognitive function [15].

The generation of the pollution map associated with a particular cycling and walking network implies the calculation of long-term noise maps based on the estimation of the equivalent noise levels (Leq) and on the calculation of the long-term maps for air pollution based only on PM10 concentrations taking into account that this pollutant has the most negative influence on human health in traditional urban environments [16]. In this first phase, the production of maps of noise and air pollution is carried out with the use of specific software, in this case, CadnaA. This software is based on the AUSTAL program for the generation of emissions and a dispersion model of pollutants, which in turn originates from a particle dispersion Lagrangian model.

The second phase, related to the contamination of distances, refers to the creation of impedances to be assigned to all sections of the street network, taking into account the data extracted from the pollution maps resulting from the first phase. It is also important to refer that several pollution maps must be produced in order to obtain a global overview of the variability of the environmental conditions over space and time. For this, the production of hourly maps is recommended. The contamination process consists on the application of a multiplicative factor to real distances that can be written as eqn (1); this factor varies according to the type of pollutant.

$$
\text { Contaminated Distance }=\text { Distance } \times \text { Factor. }
$$

The multiplicative factor for noise is defined as a linear fuzzy variable that triples the value of distances for noise levels above $75 \mathrm{dBA}$ and reduces to one-third the distance for values lower than $45 \mathrm{dBA}$. For values between 55 and $65 \mathrm{dBA}$, the factor is equal to 1.0 , which means that the distance is not affected by environmental noise.

For PM10 concentrations, a multiplicative factor was also used in the form of a linear fuzzy variable that reduces to one-third distances for values lower than $10 \mu \mathrm{g} / \mathrm{m}^{3}$ and triplicates the distances for concentrations higher than $40 \mu \mathrm{g} / \mathrm{m}^{3}$.

In this stage of the routing process, it is essential to develop a GIS working platform to integrate the air pollution and noise information with the transport network facilities, and thereby build a base of the contaminated network axes for each pollutant or for a combination of pollutants.

The third phase consists in making the generation process of healthy routes and itineraries operational, that is, after having 'contaminated' the transport network, a GIS database is produced with all contaminated distances (length of the axis). These are then used in route optimization algorithms, in order to determine a wide range of routes, including the shortest, less noisy, less polluted (with lower concentrations of air pollutants), and healthier routes. To this end, there is a variety of commercial programs offering this possibility. In this work, the Network Analyst extension of Esri's ArcInfo was used, which allows the production of several maps essential for planning and routing.

The last stage consists on the validation of the model through the evaluation of the environmental performance of the calculated routes for different impedances. Thus, the optimized routes according to a certain environmental criteria (contaminated distances) were compared with the shortest route between origins and destinations. For this, the (actual) distance and two environmental indices ( $\mathrm{i}_{\text {noise }}$ and $\mathrm{i}_{\mathrm{PM} 10}$ ) are given by eqns (2) and (3).

$$
i_{\text {noise }}=\frac{\sum_{i} l_{i} \times L_{e q_{i}}}{\sum_{i} l_{i}}[\mathrm{dBA}]
$$




$$
i_{P M 10}=\frac{\sum_{i} l_{i} \times c_{P M 10_{i}}}{\sum_{i} l_{i}}\left[\mu \mathrm{g} / \mathrm{m}^{3}\right]
$$

where: $l_{i}$ - length of the street $(\mathrm{m}) ; \operatorname{Leq}_{i}$ - equivalent continuous sound level in street (A-weighted average sound level-Leq(A)); and, $C_{P M 10 i}-$ average concentration of particles - PM10 in the street.

It can only be expected that healthy routes represent better environmental conditions in comparison with the shortest routes. However, all of these could coincide with the shortest route if a light distance contamination was applied, that is, if a higher amplitude of the 'factor' expressed in eqn (1) was used. On the other hand, if a heavy contamination was applied (e.g. if the multiplicative factor was 5.0 instead of 3.0 for concentrations higher than $40 \mu \mathrm{g} / \mathrm{m}^{3}$ ), the calculation of healthy routes would be more sensitive to this pollutant and thus would tend to privilege less polluted areas or calming areas and that would consequently lead to an increase of the total length of the route.

\section{HEALTHY ROUTES TO SCHOOL - A CASE STUDY}

In this section, an example of the application of the model of generation of healthy routes will be presented for the case of three users from distinct neighborhoods of the city of Braga to a school that encompasses all grades from kindergarten to 12 th grade (the end of secondary education and the last year before University).

The case study area of $2 \mathrm{~km}^{2}$ has many schools (around 10) and other types of public equipments, since this represents the central area of the city to which a great number of students are expected to commute daily from the surrounding neighborhoods.

The first stage of the application of the model consisted on the calculation of 24-hourly long-term noise and PM10 pollution maps for the case study area. For this, a holistic data collection was made mainly regarding the territory (terrain, road infrastructures, buildings, and other barriers) and the sources of pollution (traffic). To calculate the pollution maps, the CadnaA software was used. This program applies the Nouvelle Méthode de Prevision du Bruit des Routes (NMPB)-routes-96 method to generate the noise maps. The air pollution extension of this software makes use of the Lagrangian particulate model - AUSTAL2000, which integrates a wind field model - TalDia. In Fig. 3a and 3b, two examples of the calculated maps are presented.

According to the methodology presented in section 3, the multiplicative environmental factors due to noise and the concentration of PM10 were calculated and consequently the distance
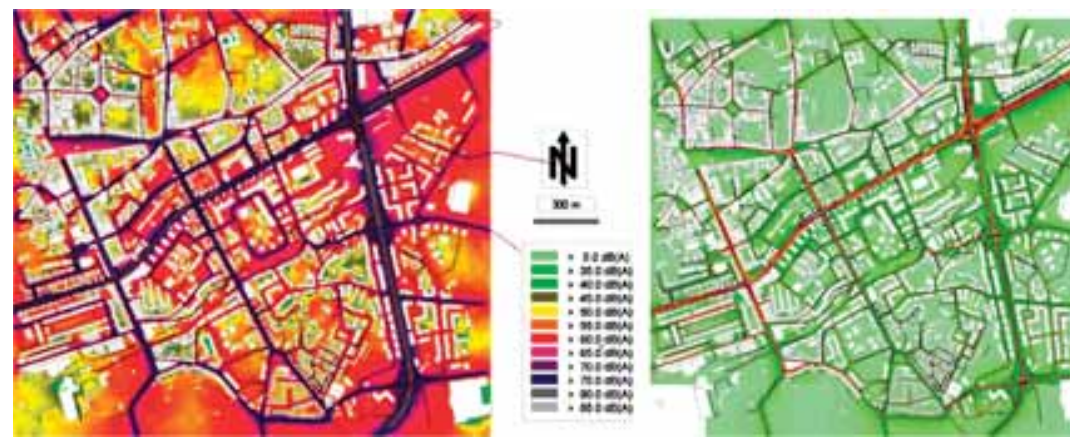

Figure 3: Long-term pollution maps for the period between 8 and 9 am: (a) noise; (b) concentration of PM10. 
contamination in a GIS platform developed in ArcGIS from Esri. Using the extension of the network analyst, it was possible to choose different impedances to be used as criteria for calculation of the different types of routes, such as the shortest, less noisy, less polluted (lower concentration of PM10) and the healthy route. In this case study, the healthy route represents an equal contribution of the effect of noise and air pollution, that is, the contaminated distance results from an average of the contaminated distances by noise and by the concentration of PM10.

In the following maps (Fig. 4) the results for the shortest routes between three possible neighborhoods A, B and C to a school located in the north of the case study area are shown. With this example, it is possible to view and understand where and how much the shortest and the healthiest routes differ.

To evaluate the environmental performance of the obtained healthier routes, the two indices proposed in section 3 were calculated as well as the comparison of the average noise levels and average concentrations of PM10 between the healthiest and the shortest routes, which are shown on Tables 1-3 and will be discussed later in section 5 of this paper.

The three neighborhoods are located around $2 \mathrm{~km}$ from the school. According to McDonald [17], the majority ( $\sim 50 \%$ ) of students walk to school, if the journey is shorter than $1.6 \mathrm{~km}$, while only $3 \%$ of students tend to walk higher distances to school. Therefore, this distance can be regarded as a high value for walking by pedestrians in a daily basis; however due to the flatness of the case study area, it can be considered valid to be used for both active modes. On the other hand, cycling can be considered the most suitable and efficient mode of transport for the school journeys in this example.

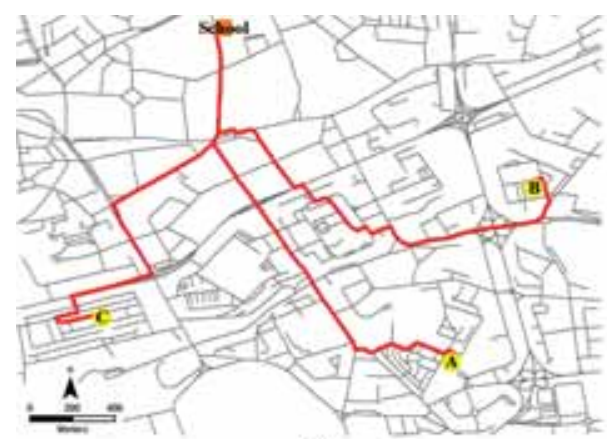

a)

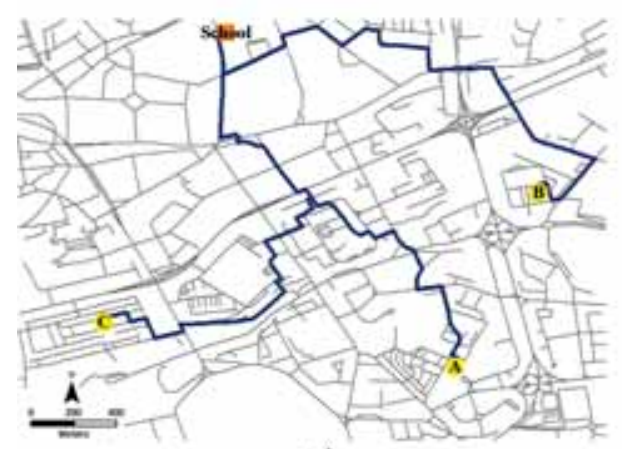

c)

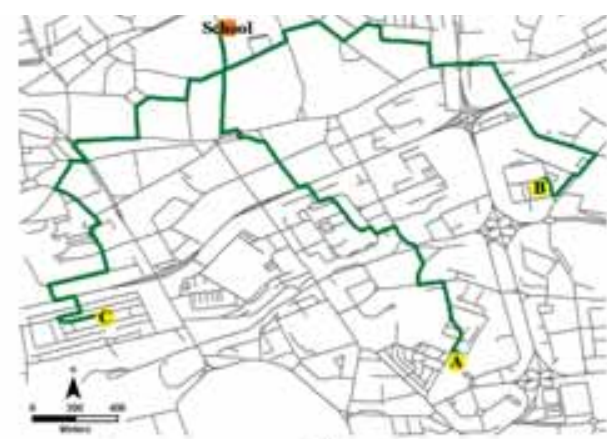

b)

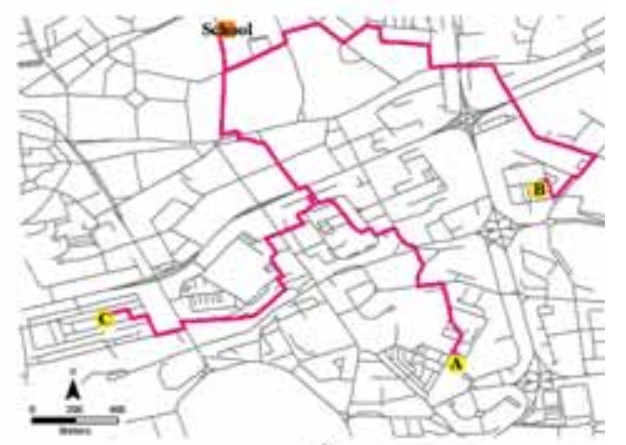

d)

Figure 4: Route maps between three neighborhoods and a school: (a) shortest routes; (b) less noisy routes; (c) less polluted (PM10); (d) healthy routes. 
Table 1: Summary of the calculation of the indices for different types of routes and a comparison with the shortest route for journeys from neighborhood A (8-9 am).

\begin{tabular}{|c|c|c|c|c|c|c|c|}
\hline \multirow[t]{2}{*}{$\begin{array}{l}\text { Routes (A to } \\
\text { school) }\end{array}$} & \multirow[b]{2}{*}{$\begin{array}{l}\text { Length } \\
\text { (m) }\end{array}$} & \multirow[b]{2}{*}{$\begin{array}{l}\text { Contaminated } \\
\text { length }(\mathrm{m})\end{array}$} & \multicolumn{2}{|c|}{ Exposure indices } & \multicolumn{3}{|c|}{ Differences to shortest route } \\
\hline & & & $\begin{array}{l}\text { Noise } \\
(\mathrm{dBA})\end{array}$ & $\begin{array}{l}\text { PM10 } \\
\left(\mu \mathrm{g} / \mathrm{m}^{3}\right)\end{array}$ & $\begin{array}{l}\text { Length } \\
(\mathrm{m})\end{array}$ & $\begin{array}{l}\text { Noise } \\
(\mathrm{dBA})\end{array}$ & $\begin{array}{l}\text { PM10 } \\
\left(\mu \mathrm{g} / \mathrm{m}^{3}\right)\end{array}$ \\
\hline Shortest & 2119.3 & 2119.3 & 71.4 & 26.8 & - & - & - \\
\hline Less noisy & 2291.8 & 4055.8 & 67.6 & - & 172.5 & -3.8 & - \\
\hline Less polluted & 2291.8 & 1785.6 & - & 23.3 & 172.5 & - & -3.5 \\
\hline Healthy & 2291.8 & 2920.7 & 67.6 & 23.3 & 172.5 & -3.8 & -3.5 \\
\hline
\end{tabular}

Table 2: Summary of the calculation of the indices for different types of routes and a comparison with the shortest route for journeys from neighborhood B (8-9 am).

\begin{tabular}{lllllllll}
\hline $\begin{array}{l}\text { Routes } \\
\text { school) }\end{array}$ & & & & & & & \\
\end{tabular}

Table 3: Summary of the calculation of the indices for different types of routes and comparison with the shortest route for journeys from the neighborhood C (8-9 am).

\begin{tabular}{lllllllll}
\hline $\begin{array}{l}\text { Routes } \\
\text { school })\end{array}$ & & & & & & & \\
\end{tabular}

In Fig. 5, it is possible to have a global overview of the types of streets that belong to the case study area, integrating the different typologies of healthy routes. It is expected that the type of streets that form the shortest, less noisy, less polluted, and healthy routes should be classified as local streets, which are more environmental friendly due to the lower level of traffic flow and speed, in comparison with local and primary distributors or the main arterial streets. 


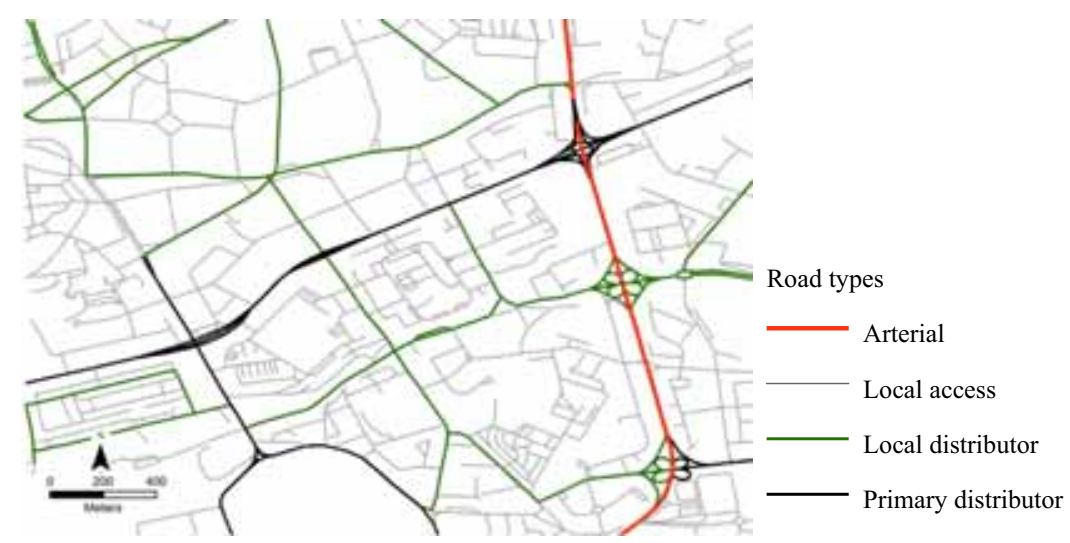

Figure 5: Functional road hierarchy of the case study network.

Safety and security are two important issues that have a huge influence in pedestrian route choice. Feelings of discomfort and insecurity can force people to avoid specific areas of a city. Although the feeling of safety usually has little in common with the actual crime rate, route choice behavior is strongly influenced by the fear of dangerous areas and pedestrians prefer to give them a wide berth [18]. The scope of this research did not include the incorporation of safety factors on pedestrian and cyclist route choice; however, it is important to enhance that the case study area is a central area of the city of Braga and within the local road network, the safety levels can be considered regular, that is, no critical area or street segment with relevant danger for pedestrians and cyclists were identified.

\section{DISCUSSION OF RESULTS}

Home-school journeys for children and teenagers who travel through urban areas often involve roads where high levels of noise, in many cases above $75 \mathrm{dBA}$, as well as high levels of air pollution can be frequently observed.

In the case study shown above, a child or teenager traveling in this kind of route every day by around $2 \mathrm{~km}$ (on average) each way would have travelled by the end of the year over 1,000 km under harmful health conditions, which may have a huge impact on the respiratory and cardiovascular systems, during the present stage of life and beyond, even in adulthood. It should be noted, however, that this yearly distance may be overestimated, since recent studies on small Portuguese cities indicate that the modes of transport to and from school may differ [19].

In the case study presented, for students walking or cycling to school in the morning (8-9 am) from neighborhoods A and B, the healthiest routes appear to be identical, at least for that time of day, since the less noisy, less polluted, and healthy routes nearly coincide. This occurs as a result of the configuration of the road network, which reduces the generation of alternatives to the shortest route, though gains in terms of the reduction in noise levels and concentration of PM10 can be clearly observed.

For students who live in neighborhood A, an average reduction of $3.5 \mu \mathrm{g} / \mathrm{m}^{3}$ of air pollution can be obtained when traveling in any of the healthiest routes, while those who live in neighborhood B can be exposed to less than $1.5 \mu \mathrm{g} / \mathrm{m}^{3}$ when using those routes. In terms of the average noise levels, a reduction of $3.8 \mathrm{dBA}$ and $2.2 \mathrm{dBA}$ can be experienced when traveling in the healthiest routes from neighborhood A and B, respectively, in comparison with the shortest route. In both cases, the length of the healthiest routes is around $175 \mathrm{~m}$ longer than the shortest route, which represents an increase of less than $10 \%$ of the total length of the journey. 
On the other hand, it was also demonstrated that it was possible to walk or cycle to school in the morning in a route with less than $6.3 \mathrm{dBA}$ in average noise levels, simply by traveling an extra $500 \mathrm{~m}$ between neighborhood $\mathrm{C}$ and the school, that is, by choosing the less noisy route. The same journey could be made with exposure to less than $4 \mu \mathrm{g} / \mathrm{m}^{3}$ of PM10 when opting for the less polluted route.

The comparison of the environmental performance for all routes calculated for school purposes from the three neighborhoods enabled to show that, in all of the cases, significant reductions in noise levels and in concentration of particles can be obtained, simply by selecting the most appropriate routes. Students who travel from neighborhood $\mathrm{C}$ will have more alternative choices to get different healthy routes to school due to their location and its relation with the road network layout.

Finally, it is important to refer that in this example healthy routes (Fig. 4d) are similar to less noisy routes (Fig. 4b), although these result from a combination of the less noisy and the less air polluted routes. This situation is explained by the lower variability of the PM10 concentration levels when compared to noise levels (Fig. 3).

\section{CONCLUSIONS}

School journeys play an important role in the mobility of urban areas, mainly in small- to mid-sized cities. The promotion of the use of active modes of transport in these journeys could represent a key issue to achieve a more sustainable urban transport system with the reinforcement of the social, economic, and environmental equity between different users, which can be improved with the choice of healthy routes instead of the shortest routes.

It is recognized that pedestrians and cyclists tend to travel between different origins and destinations through the shortest and safest route. However, sometimes they neglect environmental issues that could have a huge impact in their health and quality of life, due to the lack of specific information or to its accessibility.

The benefits of using a healthy route planner include the minimization of the effects of pollution on all citizens, with particular relevance to the most vulnerable groups of the population, such as children and teenagers, reducing potential health problems and associated costs, taking into account the specific mobility requirements of these users in contrast to motorized transport.

The application of the healthy routes model to promote the use of active modes in school journeys can be translated in direct health benefits for pedestrians and cyclists, as well as indirect benefits for the entire community. The use of these routes is expected to reduce the number of journeys by car, thus lowering the levels of pollution mainly near schools. Moreover, it promotes an increase of physical exercise and fitness of the youngest age groups.

\section{REFERENCES}

[1] Ribeiro, P. \& Mendes, J.F.G., Route planning for soft modes of transport: healthy routes. WIT Transactions on the Built Environment, 116, pp. 677-688, 2011. doi: http://dx.doi.org/10.2495/ UT110571

[2] EC, Cycling: the way ahead for towns and cities. Brussels, available at http://ec.europa.eu/ environment/cycling/cycling_en.pdf

[3] EC, Attitudes on issues related to EU Transport Policy. Brussels, available at http://ec.europa. eu/public_opinion/flash/fl_206b_en.pdf

[4] Hall R.P. \& Sussman J.M., Promoting the concept of sustainable transportation within the Federal System - The need to reinvent the U.S. DOT, TRB Paper 07-0565, 2006. 
[5] Jones, P., Natalya, B. \& Marshall, S. Link \& Place-A Guide to Street Planning and Design, Landor Publishing: London, 2007.

[6] WCED, Our Common Future (Brundtland report), Oxford University Press: Oxford (U.K.), 1987.

[7] FHWA, Federal Highway Administration University Course on Bicycle and Pedestrian Transportation. US Department of Transportation: Washington, D.C. 2006.

[8] Ribeiro, P., Mendes, J.F.G. \& Fontes, A., A mobilidade sustentável em aglomerados de pequenas dimensões. Revista Minerva - Pesquisa \& Tecnologia, 5(2), pp. 149-158. ISBN: 978-8585205-84-3, 2008.

[9] Morris, J.N. \& Hardman, A.E., Walking to health. Sports Medicine, 23(5), pp. 306-332, 1997. doi: http://dx.doi.org/10.2165/00007256-199723050-00004

[10] EC, Green Paper: Towards a new culture for urban mobility, available at http://ec.europa.eu/ transport/clean/green_paper_urban_transport/doc/2007_09_25_gp_urban_mobility_en.pdf

[11] Google maps, available at http://maps.google.pt

[12] Galanis, A. \& Eliou, N., Grading methodology of the pedestrian urban road environment. WSEAS Transactions on Environment and Development, 6(7), pp. 157-166, 2011.

[13] Eliou, N., Galanis, A. \& Proios, A., Evaluation of the bikeability of a Greek city: case study "city of Volos". WSEAS Transactions on Environment and Development, 8(5), pp. 545-555, 2009.

[14] World Health Organization, WHO Air Quality Guidelines for particulate matter, ozone, nitrogen oxide and sulphur dioxide: global update 2005. World Health Organization, Report on a Working Group meeting, 2005.

[15] European Environment Agency, Good practice on noise exposure and potential health effects, European Environment Agency Technical report - No 11, ISSN 1725-2237, 2010.

[16] Ribeiro, P., Healthy routes for soft modes of transport. PhD Thesis. Universidade do Minho, Portugal. (in Portuguese), 2011.

[17] McDonald, N.C., Children's mode choice for the school trip: the role of distance and school location in walking to school. Transportation, 35(1), pp. 23-35, 2008. doi: http://dx.doi.org/ 10.1007/s11116-007-9135-7

[18] Millonig, A. \& Schetchtner, K., Decision loads and route qualities for pedestrians - key requirements for the design of pedestrian navigation services. Pedestrian and Evacuation Dynamics 2005, 2, pp. 109-118, 2007.

[19] Alves, R.M., Duarte, S.A. \& Calcinha, M.I. Travel to school and urban structure in medium and small sized cities: a case study of Castelo Branco. WIT Transactions on the Built Environment, 116, pp. 341-352, 2011. doi: http://dx.doi.org/10.2495/UT110291 